\title{
BMJ Open COVID-19 mortality effects of underlying health conditions in India: a modelling study
}

\author{
Paul Novosad (D) , ${ }^{1}$ Radhika Jain (D) , ${ }^{2}$ Alison Campion (D), ${ }^{3}$ Sam Asher (i) ${ }^{4}$
}

To cite: Novosad $P$, Jain $R$, Campion A, et al. COVID-19 mortality effects of underlying health conditions in India: a modelling study. BMJ Open 2020;10:e043165. doi:10.1136/ bmjopen-2020-043165

- Prepublication history and additional material for this paper are available online. To view these files, please visit the journal online (http://dx.doi. org/10.1136/bmjopen-2020043165).

Received 29 July 2020 Revised 02 November 2020 Accepted 25 November 2020

Check for updates

(C) Author(s) (or their employer(s)) 2020. Re-use permitted under CC BY-NC. No commercial re-use. See rights and permissions. Published by BMJ.

${ }^{1}$ Economics, Dartmouth College, Hanover, New Hampshire, USA

${ }^{2}$ Stanford University, Stanford, California, USA

${ }^{3}$ Development Data Lab

Washington, DC, USA

${ }^{4}$ International Economics, Johns Hopkins University Paul H Nitze School of Advanced International Studies, Washington, DC, USA

Correspondence to

Dr Paul Novosad;

paul.novosad@dartmouth.edu

\section{ABSTRACT}

Objective To model how known COVID-19 comorbidities affect mortality rates and the age distribution of mortality in a large lower-middle-income country (India), and to identify which health conditions drive differences with high-income countries.

Design Modelling study.

Setting England and India.

Participants Individual data were obtained from the fourth round of the District Level Household Survey and Annual Health Survey in India, and aggregate data were obtained from the Health Survey for England and the Global Burden of Disease, Risk Factors and Injuries Studies.

Main outcome measures The primary outcome was the modelled age-specific mortality in each country due to each COVID-19 mortality risk factor (diabetes, hypertension, obesity and respiratory illness, among others). The change in overall mortality and in the share of deaths under age 60 from the combination of risk factors was estimated in each country.

Results Relative to England, Indians have higher rates of diabetes (10.6\% vs $8.5 \%$ ) and chronic respiratory disease (4.8\% vs $2.5 \%)$, and lower rates of obesity $(4.4 \%$ vs $27.9 \%)$, chronic heart disease ( $4.4 \%$ vs $5.9 \%$ ) and cancer $(0.3 \%$ vs $2.8 \%)$. Population COVID-19 mortality in India, relative to England, is most increased by uncontrolled diabetes $(+5.67 \%)$ and chronic respiratory disease $(+1.88 \%)$, and most reduced by obesity $(-5.47 \%)$, cancer $(-3.65 \%)$ and chronic heart disease $(-1.20 \%)$.

Comorbidities were associated with a $6.26 \%$ lower risk of mortality in India compared with England. Demographics and population health explain a third of the difference in share of deaths under age 60 between the two countries. Conclusions Known COVID-19 health risk factors are not expected to have a large effect on mortality or its age distribution in India relative to England. The high share of COVID-19 deaths from people under age 60 in low- and middle-income countries (LMICs) remains unexplained. Understanding the mortality risk associated with health conditions prevalent in LMICs, such as malnutrition and HIV/AIDS, is essential for understanding differential mortality.

\section{INTRODUCTION}

The number of cases of COVID-19 continues to rise around the world. A growing share of cases is coming from low- and middle-income

\section{Strengths and limitations of this study}

- This study modelled the extent to which demographics and the population prevalence of COVID-19 mortality risk factors are likely to affect mortality in India, a major lower-middle-income country.

- This study distinguished between controlled and uncontrolled health conditions (such as diabetes), a difference that may significantly affect population risk.

- This study used multivariate HRs from the largest sample analysis of risk factors for COVID-19 mortality to date ( $\mathrm{N}=17278392)$, which is essential because bivariate HRs may overestimate the effect of pre-existing health conditions that increase with age.

- In addition to modelling total mortality, this study modelled the age distribution of deaths, which has been very different in low- and middle-income countries (LMICs) and high-income countries.

- The key limitation of this study is that there are almost no large sample analyses describing the additional risk of COVID-19 mortality associated with health conditions that are more common in LMICs than in high-income countries, such as protein calorie malnutrition, micronutrient deficiency and HIV/ AIDS.

countries (LMICs) in Asia, Africa and the Americas that were largely spared in the initial stages of the pandemic. ${ }^{1}$ Because the severity of infection increases substantially with age, forecasts have projected much lower aggregate mortality rates in LMICs than in highincome countries. ${ }^{2-4}$

However, the reported fatality numbers from LMICs to date have suggested a much greater share of COVID-19 deaths among the young. As of May 2020, 30.5\% of deaths in Brazil occurred in those under age 60, whereas $27 \%$ of deaths in Mexico occurred in those under age $50 .{ }^{5-7}$ As of July 2020, 47\% of COVID-19 deaths in India occurred in those under age 60, whereas a particular study of Tamil Nadu and Andhra Pradesh found 54\% of deaths occurred in those under age $65 .{ }^{89}$ 
In contrast, individuals under age 65 have accounted for only $5 \%-13 \%$ of deaths in 10 European countries and Canada and $8 \%-24 \%$ in US states. ${ }^{10}$ It is not presently known whether the different age pattern of deaths in LMICs is driven by erroneous reporting, differences in infection patterns, younger populations or different rates of COVID-19 comorbidities in the underlying populations.

Many modelling studies have presumed that worse population health in LMICs will lead to excess mortality or else have ignored differential population health as a factor entirely. ${ }^{411} 12$ To date, there has been limited analysis of the prevalence in LMICs of the specific conditions associated with increased COVID-19 severity, such as diabetes, obesity, cardiovascular disease, hypertension and chronic kidney disease, or of how they change the expected level and age distribution of mortality. ${ }^{43-16}$ Some studies have adjusted mortality estimates for population comorbidities by treating all comorbidities as equivalent or by multiplying the mortality rate by a fixed amount to adjust for population health. ${ }^{17-20}$ One study combined condition-specific prevalence and HRs from a sample of hospitalisations, but excluded obesity and uncontrolled diabetes, and did not examine mortality or the age distribution of mortality as outcomes. ${ }^{21}$

Using England as a benchmark, this study examines how comorbidities understood to increase COVID-19 mortality are likely to affect COVID-19 mortality rates in aggregate and across the age distribution in India, identifying the specific risk factors with the largest mortality effects. We further study the extent to which accounting for differences in demographics and underlying health conditions can explain the increased share of deaths among the young in India relative to England.

Our analysis focuses on India and on the COVID-19 risk factors that are currently documented. At the time of writing, India has the second highest number of cumulative COVID-19 infections in the world and one of the highest growth rates in infections of any major country, making it an essential population to study. ${ }^{1}$ The methodology is readily adjusted to account for new risk factors or data from other countries and may be useful for modelling the epidemic in a range of LMICs.

\section{METHODS}

Our approach requires three types of data: (1) the relative risk of COVID-19 mortality associated with gender, age and each health condition; (2) the age-specific prevalence of each health condition in England and India; and (3) the age and gender distributions for the two countries.

\section{Estimates of relative risk of COVID-19 mortality from comorbidities}

We obtained estimates of COVID-19 mortality risk for a wide range of comorbidities from the OpenSAFELY study, a closed cohort study of 17278392 adults from
England..$^{22}$ This was the largest analysis of comorbidities associated with COVID-19 mortality to date and one of the few studies that estimates risk factors in a multivariate model adjusting for age, sex and other health conditions. This adjustment is important because many COVID-19 comorbidities are increasing in age and their HRs are thus biased upwards in analyses not adjusting for age.

The OpenSAFELY study enrolled all individuals registered with a general practice within The Phoenix Partnership system on 1 February 2020, who were aged 18 years or older on enrolment, who had at least 1 year of medical history within the system and who had recorded age and sex. The underlying data set represents $40 \%$ of the population of England, and the prevalence of health conditions in the study cohort is similar to estimates of population prevalence in England (online supplemental appendix $\mathrm{p} 4$ ). Patients were followed through 6 May. The outcome was in-hospital death among people with confirmed COVID-19 infections. HRs for mortality from a Cox proportional-hazards model were estimated for a comprehensive list of risk factors described in other studies, adjusted for sex, age and all other risk factors. As patient-level data from OpenSAFELY are not publicly available, we extracted HRs from the paper reporting results of the analysis. ${ }^{22}$ In the absence of patient-level COVID-19 mortality data with comorbidity information in India, we assumed that comorbidity-associated HRs were the same in India as in England.

Ideally, HRs would measure mortality risk conditional on infection, rather than on registration with a general practice (as in OpenSAFELY) or hospitalisation (as in prior work). ${ }^{21}{ }^{23}$ The HRs in this study therefore reflect combined mortality and infection risk; the analysis assumes that pre-existing health conditions are not significant predictors of infection. Reassuringly, HRs measuring mortality risk conditional on hospitalisation in other studies are similar to those used here. ${ }^{11}$

\section{Demographics and risk factor prevalence in India and England} Age distributions and age-specific sex ratios for India and England were obtained from official censuses.

We obtained data on age-specific prevalence of health risk factors for India and England from multiple sources, prioritising biomarker data where available and matching definitions as closely as possible to the conditions for which HRs are available. We restrict samples to ages 18-99 for consistency with the HRs.

For India, we aggregated individual-level biomarker data from two public population health surveys for obesity, diabetes and hypertension. The fourth round of the Indian District Level Household Survey and the second round of the Annual Health Survey were conducted between 2012 and 2014; they jointly cover $94 \%$ of the Indian population and provide the most recent nationwide direct measures of height, weight, fasting plasma glucose (FPG) and blood pressure (BP) for adults of all ages in India. Details of data set construction are provided in online supplemental appendix p 1. 
For England, age-specific prevalences of obesity, hypertension and diabetes were obtained from the nationally representative 2018 Health Survey for England, which collected symptoms and medical diagnoses for a range of illnesses, as well as direct measures of height, weight, BP and glycated haemoglobin (HbAlc) ${ }^{24}$

Body mass index was classified into no evidence of obesity $\left(<30 \mathrm{~kg} / \mathrm{m}^{2}\right)$, obese class 1 or $2\left(30-39.9 \mathrm{~kg} / \mathrm{m}^{2}\right)$ and obese class $3\left(40+\mathrm{kg} / \mathrm{m}^{2}\right)$. Hypertension was defined as systolic BP $\geq 140 \mathrm{~mm} \mathrm{Hg}$ or diastolic BP $\geq 90 \mathrm{~mm} \mathrm{Hg}$ (uncontrolled) or a medical diagnosis of hypertension with BP below the thresholds (controlled). The prevalence of controlled and uncontrolled hypertension was reported separately but combined in the risk estimation for consistency with OpenSAFELY. OpenSAFELY classified controlled diabetes as HbA1c $>51 \mathrm{mmol} / \mathrm{mol}$ and HbAlc $<58 \mathrm{mmol} / \mathrm{mol}$, and uncontrolled diabetes as HbA1c $\geq 58 \mathrm{mmol} / \mathrm{mol}$. Corresponding thresholds for the one-time FPG measures in the Indian data set are not well defined. In England, the prevalence was reported based on a threshold of HbAlc $\geq 48 \mathrm{mmol} / \mathrm{mol}(6.5 \%)$. Therefore, we followed the standard screening and diagnosis thresholds recommended by the WHO and International Diabetes Federation and defined uncontrolled diabetes in India as a plasma glucose reading $\geq 126 \mathrm{mg} / \mathrm{dL}$ $(7.0 \mathrm{mmol} / \mathrm{L})$ if fasting or $\geq 200 \mathrm{mg} / \mathrm{dL}(11.1 \mathrm{mmol} / \mathrm{L})$ if not fasting. We used the corresponding recommended threshold of $\mathrm{HbA} 1 \mathrm{c} \geq 48 \mathrm{mmol} / \mathrm{mol}(6.5 \%)$ for uncontrolled diabetes in England. ${ }^{25}$ In both countries, we classified individuals with biomarkers below the thresholds but with a diagnosis of diabetes as having controlled diabetes.

Age-specific prevalence for asthma, chronic heart disease, kidney disease, stroke, dementia, haematological malignancies and all other cancers was drawn from the Global Burden of Diseases, Risk Factors and Injuries Studies (GBD) for India and England. ${ }^{26}$ OpenSAFELY reports separate HRs for cancers diagnosed $<1$ year ago, $1-4.9$ years ago and $\geq 5$ years ago; because the year of diagnosis is unavailable in GBD, we used a single classification for each class of cancers and the HR for diagnosis $<1$ year ago. For chronic respiratory disease, we used chronic obstructive pulmonary disease (COPD) prevalence from the GBD for India and modelled COPD prevalence from the Clinical Practice Research Datalink cohort database for England. ${ }^{27}$ GBD prevalence of Parkinson's disease, epilepsy, multiple sclerosis and motor neuron disease was combined and classified as neurological disorders.

The following risk factors were not available for India and were excluded from the analysis for both England and India for comparability: fibrosing lung disease, bronchiectasis or cystic fibrosis, lupus, asthma with no recent oral corticosteroid use, cancers diagnosed more than a year ago, organ transplant and spleen disease. Given that the relationship between smoking and COVID-19 mortality remains under debate, we excluded it from the analysis. ${ }^{28}$ We also excluded ethnicity and socioeconomic status, which cannot be measured comparably across England and India and are unlikely to have similar relative risk in the two countries. Where aggregate data were available only in coarse age bins, we used non-linear interpolation to reaggregate the data into age bins matching the HR data.

Estimating the contribution of health conditions to population COVID-19 mortality risk

The OpenSAFELY study reports HRs for each age group, sex and health condition with women aged 50-59 years with no conditions as the reference group. ${ }^{22}$ We transform the HR for each health condition $c$ into a relative risk $\left(R R_{c}\right)$ assuming a population mortality rate $r$ of $1 \%$ :

$$
R R_{c}=\left(1-e^{H R_{c} \ln (1-r)}\right) / r
$$

To obtain continuous relative risk for age, we used a polynomial interpolation for the log HR at each age, renormalising with age 50 as the reference group (online supplemental appendix p 5).

The additional population mortality risk associated with a given health condition increases with the condition's relative risk for COVID-19 mortality and with its prevalence. We defined the age-specific and conditionspecific population relative risk $\mathrm{PRR}_{\mathrm{a}, \mathrm{c}}$ of condition $c$ at age $a$ as follows:

$$
P R R_{a, c}=R R_{c} \times P R E V_{a, c}+\left(1-P R E V_{a, c}\right)
$$

where $P R E V_{a, c}$ is the prevalence of condition $c$ at age $a$, and $P R R_{a, c}$ describes the proportional increase in mortality at age $a$ associated with health condition $c$.

We combined PRRs to obtain an age-specific population relative risk of mortality arising from the combined prevalence of all the health conditions:

$$
P R R_{a}=\prod_{c \in C} P R R_{a, c}
$$

$P R R_{a}$ isolates the expected mortality difference at each age between India and England that is driven by the combined prevalence of all the health conditions studied. This approach implicitly assumes that the health conditions are uncorrelated with each other. Without microdata on the full set of health conditions, this assumption is unavoidable, but will bias the England versus India comparison only if the correlation of health conditions is substantially different in the two countries. We explore the possible extent of this bias in the online supplemental appendix. Using age-specific prevalence, our analysis fully accounts for the substantial correlations between age and health conditions.

We next calculated the increase in population mortality from each health condition across all ages, taking into account the age-specific prevalence of each health condition, its relative risk and the population share at each age. The condition-specific population relative risk of each health condition across the full population $\left(P R R_{c}\right)$ is given by the following equation:

$$
\left.P R R_{c}=\sum_{a \in[18,99]}\left(\operatorname{PRR}_{a, c} * \text { POPSHARE }\right)_{a}\right)
$$


$P R R_{c}$ is greater when the relative risk of condition $c$ is higher $\left(R R_{c}\right)$ and when its prevalence is higher at ages with higher population. The combined effect on population mortality of all the health conditions is given by the product of each condition-specific $P R R_{c}$.

Finally, we aggregated the population relative risks across health conditions to model the age distribution of deaths in each country. The number of deaths at each age $N_{a}$ is the product of the mortality rate of the reference group (50-year-old women with no other risk factors), the population at age $a$, the age-specific population relative risk of the full set of health conditions $\left(P R R_{a}\right)$, the PRR of gender and the direct relative risk of COVID-19 mortality for an individual at age $a\left(R R_{a}\right)$ :

$$
N_{a}=r \times P O P_{a} \times P R R_{a} \times P R R_{a, \text { male }} \times R R_{a}
$$

We plotted the age distribution of deaths as shares of all deaths rather than in levels, eliminating the need to assume a reference group mortality rate. We summarised the shape of the distribution by reporting the share of expected deaths in each country that are under the age of 60 . We present results from three models: (1) England's demographics and health distribution, (2) India's demographics and health distribution and (3) India's demographics but England's age-specific prevalence of health risk factors. The third model allowed us to examine the mortality shift that comes from differences in population health alone.

\section{Role of the funding source}

The funder of the study had no role in study design, data collection, data analysis, data interpretation or writing. The corresponding author had full access to the data in the study and had final responsibility for the decision to submit for publication.

\section{Patient and public involvement}

Because this study uses existing epidemiological data, it was not appropriate to involve patients or the public in the research.

\section{RESULTS}

\section{Prevalence of COVID-19 risk factors in India and England}

Demographic characteristics and overall prevalence of risk factors are substantially different in India relative to England (table 1). In all, $83.7 \%$ of Indian adults are below the age of 60, compared with $69.9 \%$ of English adults. Indians have substantially lower rates of obesity and cancer $(4.4 \%$ and $0.3 \%$ in India compared with $27.9 \%$ and $2.8 \%$ in England), but higher rates of uncontrolled diabetes, kidney disease and chronic liver disease $(8.9 \%$, 9.7\% and 5.3\% in India compared with $2.1 \%, 5.6 \%$ and $2.6 \%$ in England).

We show differences in age-specific prevalence between India and England for the conditions for which we have biomarkers in India and are more precisely estimated (figure 1), as well as age-specific prevalence of all conditions for both countries (online supplemental appendix
Table 1 Prevalence of COVID-19 risk factors in India and England

\begin{tabular}{lcc}
\hline & \multicolumn{2}{c}{ Prevalence (\%) } \\
\cline { 2 - 3 } & India & England \\
\hline Ages 18-39 & 50.2 & 36.6 \\
\hline Ages 40-49 & 19.2 & 16.3 \\
\hline Ages 50-59 & 14.3 & 17.0 \\
\hline Ages 60-69 & 10.3 & 13.3 \\
\hline Ages 70-79 & 4.6 & 10.4 \\
\hline Ages 80-99 & 1.5 & 6.3 \\
\hline Male & 47.1 & 48.9 \\
\hline Diabetes (controlled) & 1.7 & 6.4 \\
\hline Diabetes (uncontrolled) & 8.9 & 2.1 \\
\hline Hypertension & 28.2 & 28.0 \\
\hline Obese (classes 1 and 2) & 4.0 & 24.8 \\
\hline Obese (class 3) & 0.4 & 3.1 \\
\hline Chronic heart disease & 4.4 & 5.9 \\
\hline Chronic respiratory disease & 4.8 & 2.5 \\
\hline Asthma & 2.5 & 9.2 \\
\hline Kidney disease & 9.7 & 5.6 \\
\hline Chronic liver disease & 5.3 & 2.6 \\
\hline Haematological cancer & 0.0 & 0.2 \\
\hline Non-haematological cancer & 0.3 & 2.6 \\
\hline Stroke, dementia & 1.3 & 1.5 \\
\hline Other neurological conditions & 0.0 & 0.1 \\
\hline Psoriasis, rheumatoid & 1.0 & 2.4 \\
\hline Other immunosuppressive conditions & 0.1 & 0.1 \\
\hline
\end{tabular}

p 3). The overall rates of diabetes are higher in India at all ages, but diabetes in India is overwhelmingly uncontrolled, whereas three-quarters of diabetes is controlled in England. Hypertension (the sum of controlled and uncontrolled) is higher in India at young ages (31.3\% for ages 40-49 in India and $18.3 \%$ in England) but lower at higher ages $(52.3 \%$ at ages $70-79$ in India and $61.3 \%$ in England) and is overwhelmingly uncontrolled. Conversely, obesity rates are higher at all ages in England.

\section{Relative risk of COVID-19 mortality from combined risk factors in India and England}

The age-specific population relative risk of COVID-19 mortality from all health conditions combined $\left(P R R_{a}\right)$ is higher in India than in England at nearly all ages, but the difference in $P R R_{a}$ between the two countries is below $15 \%$ at every age and highest between ages 40 and 80 (figure 2).

$P R R_{a}$ reflects the age-specific prevalence and associated COVID-19 mortality risk from all health conditions combined. Taking risk, prevalence and population at every age into account provides the full population relative risk of COVID-19 mortality from each health condition $\left(P R R_{c}\right)$-or the proportional increase in population 


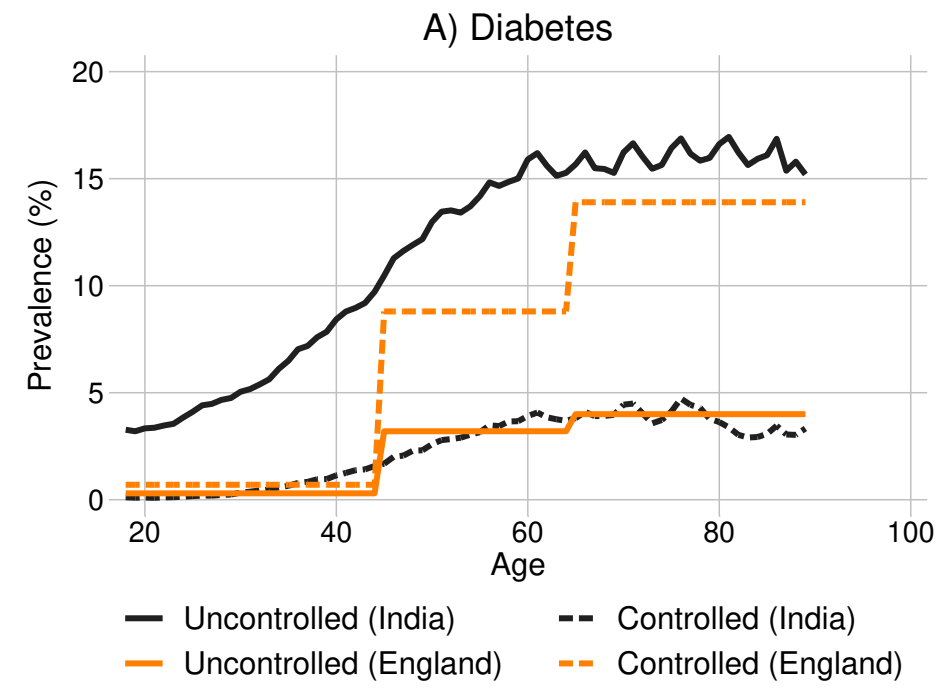

B) Hypertension

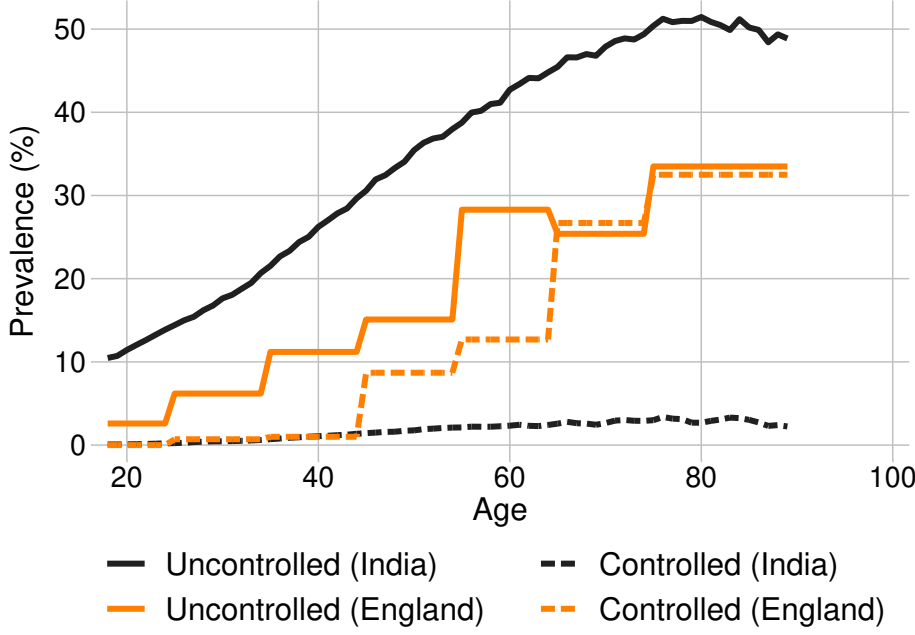

C) Obesity

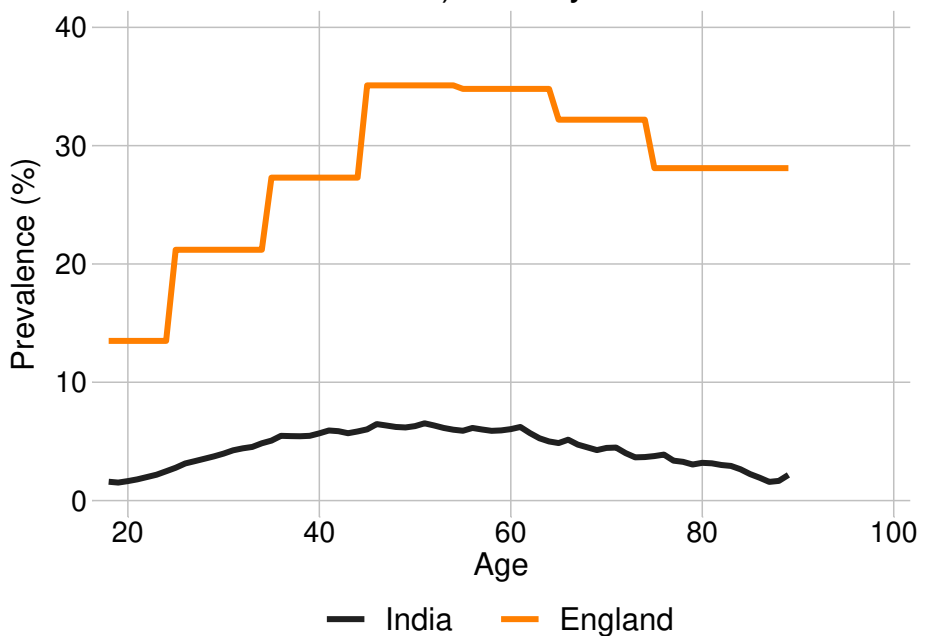

Figure 1 Prevalence of (A) diabetes, (B) hypertension and (C) obesity in India and England. 


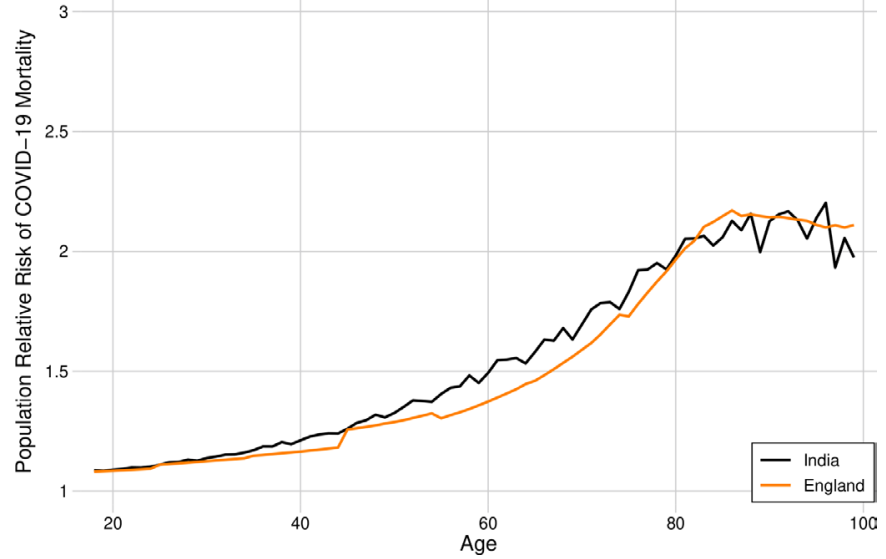

Figure 2 Age-specific population relative risk of COVID-19 mortality from all health conditions $\left(P R R_{a}\right)$.

mortality across all ages associated with each health condition (table 2).

Uncontrolled diabetes, which is associated with substantial mortality risk $\left(R R_{c}=1.94\right)$, increases total mortality by $7.8 \%$ in India $\left(P R R_{c}=1.078\right)$, but only by $2.0 \%$ in England $\left(P R R_{c}=1.020\right)$, reflecting its significantly higher prevalence in India at all ages. In contrast, controlled diabetes, more common in England than in India, is associated with $2.0 \%$ higher mortality in England and only $0.4 \%$ in

Table 2 Population relative risk of COVID-19 mortality from each health condition (PRRc) .

\begin{tabular}{|c|c|c|c|}
\hline & \multirow{2}{*}{$\begin{array}{l}\text { Individual } \\
\text { relative risk }\end{array}$} & \multicolumn{2}{|c|}{$\begin{array}{l}\text { Population } \\
\text { relative risk } \\
\left(P R R_{c}\right)\end{array}$} \\
\hline & & India & England \\
\hline Diabetes (controlled) & 1.31 & 1.004 & 1.020 \\
\hline Diabetes (uncontrolled) & 1.94 & 1.078 & 1.020 \\
\hline Hypertension & 0.89 & 0.971 & 0.969 \\
\hline Obese (classes 1 and 2) & 1.15 & 1.006 & 1.037 \\
\hline Obese (class 3) & 1.91 & 1.004 & 1.028 \\
\hline Chronic heart disease & 1.17 & 1.008 & 1.021 \\
\hline $\begin{array}{l}\text { Chronic respiratory } \\
\text { disease }\end{array}$ & 1.62 & 1.035 & 1.015 \\
\hline Asthma & 1.13 & 1.003 & 1.011 \\
\hline Kidney disease & 1.42 & 1.050 & 1.046 \\
\hline Chronic liver disease & 1.73 & 1.042 & 1.024 \\
\hline Haematological cancer & 2.79 & 1.000 & 1.007 \\
\hline $\begin{array}{l}\text { Non-haematological } \\
\text { cancer }\end{array}$ & 1.71 & 1.002 & 1.033 \\
\hline Stroke, dementia & 2.15 & 1.016 & 1.041 \\
\hline $\begin{array}{l}\text { Other neurological } \\
\text { conditions }\end{array}$ & 2.56 & 1.002 & 1.002 \\
\hline Psoriasis, rheumatoid & 1.19 & 1.002 & 1.007 \\
\hline $\begin{array}{l}\text { Other } \\
\text { immunosuppressive } \\
\text { conditions }\end{array}$ & 1.69 & 1.001 & 1.001 \\
\hline
\end{tabular}

India $\left(P R R_{c}=1.020 \mathrm{vs} 1.004\right)$. In addition to uncontrolled diabetes, the health conditions associated with the largest increases in mortality in India are kidney disease $\left(P R R_{c}\right.$ $=1.050)$ and chronic respiratory disease $\left(P R R_{c}=1.035\right)$. In England, the most consequential health conditions are obesity (combined $P R R_{c}$ across all obesity classes $=1.065$ ) and kidney disease $\left(P R R_{c}=1.046\right)$.

Comparing the percentage difference between $P R R_{c}$ of each health condition between India and England (figure 3), the condition with the largest differential impact on mortality between the two countries is uncontrolled diabetes, which is associated with $5.67 \%$ higher population mortality in India relative to England. Mortality in India relative to England is also increased by chronic respiratory disease $(+1.88 \%)$ and chronic liver disease $(+1.73 \%)$, but decreased by the differential prevalence of obesity (combined $-5.47 \%)$, cancer $(-3.65 \%$ ) and stroke/dementia $(-2.47 \%)$. No other risk factor has an effect of greater than $\pm 2 \%$ on India's relative mortality. The combined effect of health conditions leads to $6.26 \%$ higher mortality in England than in India, reflecting England's higher age-specific prevalence of certain conditions like obesity and cancer, as well as its older age structure that increases population share at ages with worse health. This differential mortality risk does not include the direct effect of older age, which is associated with substantial risk $\left(R R_{a}=6.08\right.$ for ages $70-80$ and 20.61 for age $>80$ ) and magnifies England's mortality disadvantage substantially.

Combining the population relative risk from health conditions with the direct effect of demographics on mortality, we modelled the density of deaths across the age distribution (figure 4). In England, 9.4\% of modelled deaths are below age 60, closely matching the $6.5 \%$ observed in England through May 2020 and reported in the OpenSAFELY data set. In India, $23.5 \%$ of modelled deaths are below age 60 , which is substantially lower than the 50\% observed in case reports. Applying England's age-specific prevalence of health conditions to India's demographic distribution, to isolate the effect of health conditions from demographics, results in a distribution nearly identical to the India model. In other words, differences in health conditions between India and England have almost no effect on mortality, indicating that the higher share of deaths in younger populations in India comes from the demographic distribution alone.

In the online supplemental appendix, we test sensitivity to uncertainty in prevalences and HRs (online supplemental appendix pp 6-8). The latter estimates cover alternate HRs estimated from other studies. ${ }^{21}{ }^{29}$ We also test sensitivity to alternate assumptions about covariance of health conditions (online supplemental appendix $p$ 9). In all cases, we find that the population relative risk from health conditions in England is greater than that in India, and that accounting for health conditions cannot explain any of the higher incidence of mortality among the young in India relative to England. 


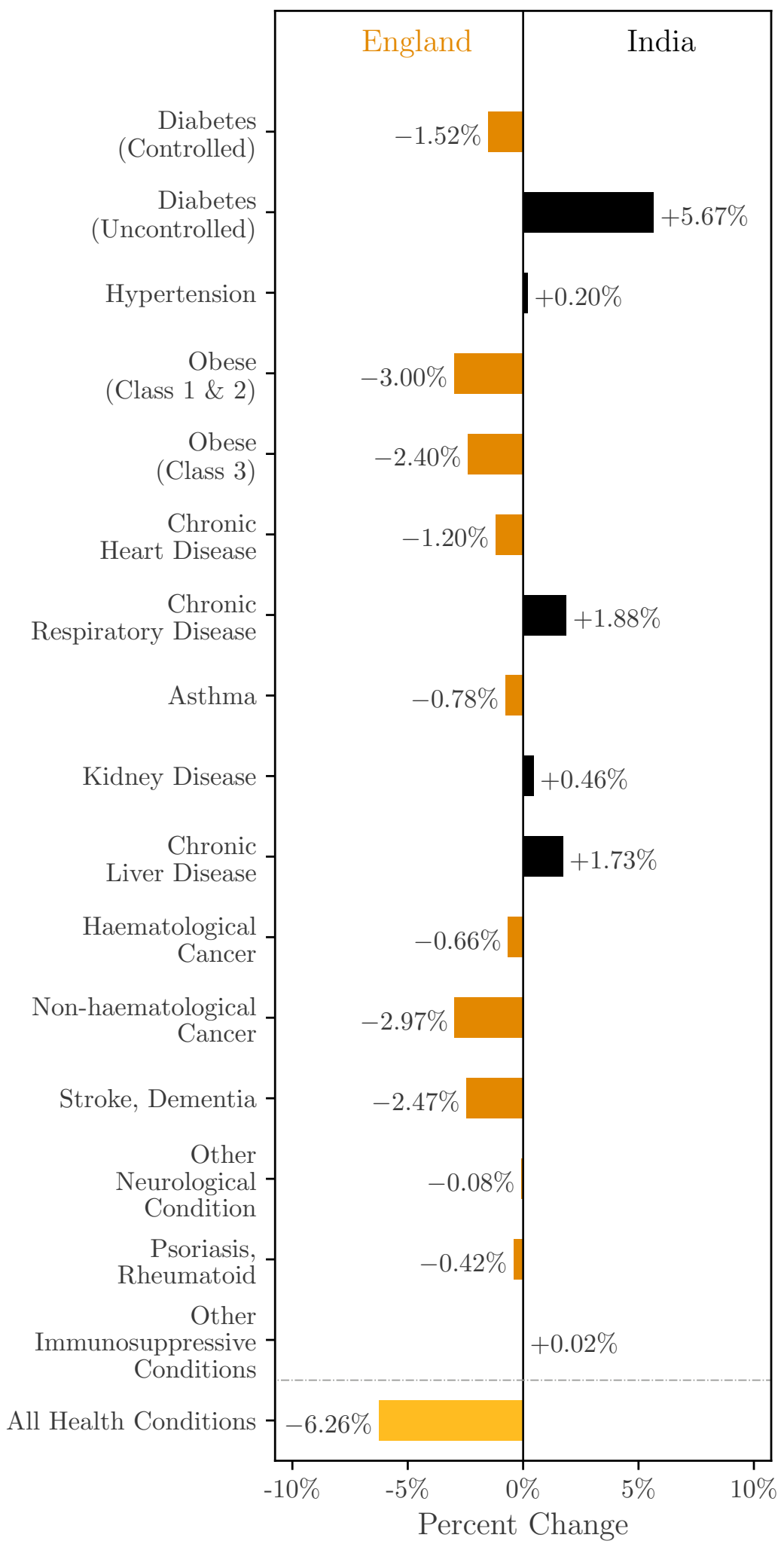

Figure 3 Percent change in population relative risk of COVID-19 mortality from each health condition $\left(P R R_{c}\right)$ in India versus England.

\section{DISCUSSION}

We used the best publicly available data on population health to examine the extent to which demographics and pre-existing health conditions known to be associated with COVID-19 mortality can account for the disproportionately high share of COVID-19 deaths in younger populations observed in India relative to England. We show that differences in population health do not 


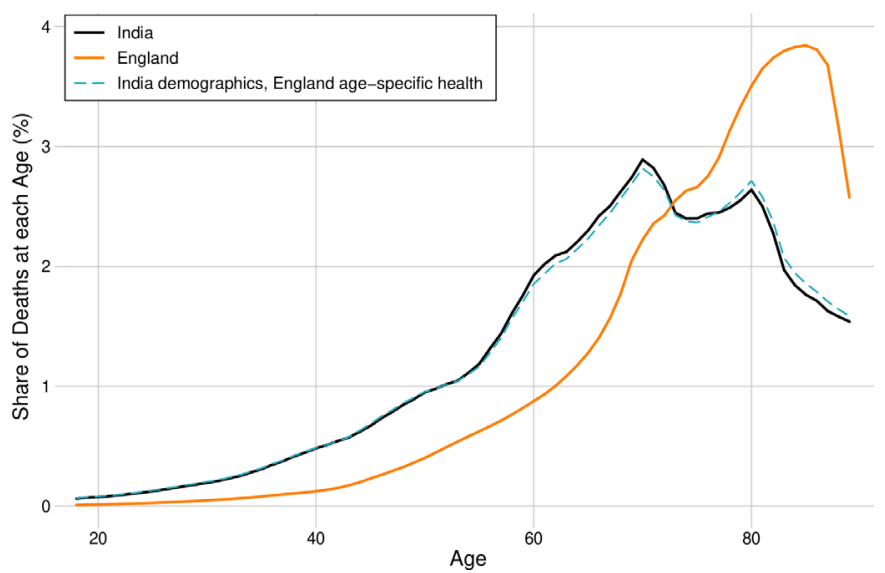

Figure 4 Modelled age distribution of COVID-19 mortality.

significantly shift the relative age distribution of disease severity and slightly lower aggregate mortality in India relative to England. Higher prevalence of diabetes and respiratory illness increases mortality risk relative to England, but these effects are offset by lower rates of obesity, heart disease and cancer. While the Indian age distribution substantially shifts expected mortality towards the young, it explains only a third of the difference in the share of deaths under 60 compared with England.

Epidemiological models have typically assumed that comorbidities will exacerbate the mortality of COVID-19 in India and other LMICs relative to high-income countries. We found that comorbidities identified as key risk factors in high-income countries are not associated with higher expected mortality in India relative to England, in aggregate or among the young. This suggests that understanding the other factors that may explain the differential mortality among the young observed in lower income contexts, such as different patterns of infection, under-resourced health systems or comorbidities unique to LMICs, should be a priority for further research.

This study improves on prior work by examining the extent to which comorbidities can explain the younger incidence of COVID-19 mortality in LMICs, by estimating mortality effects of specific comorbidities and by calibrating a model with a comprehensive set of comorbidity HRs drawn from a large-sample multivariate analysis of COVID-19 mortality. Models calibrated with bivariate HRs or raw prevalences of comorbidities among severe cases are likely to overestimate the effect of pre-existing health conditions because of the significant increase in all comorbidities with age alongside the direct effect of age on COVID-19 mortality.

The key limitation of this study is that there are virtually no data on the COVID-19 mortality risks associated with health conditions that are more common in LMICs than in high-income countries, such as protein calorie malnutrition, micronutrient deficiency and HIV/AIDS. ${ }^{4}$ If these conditions make individuals more susceptible to severe infections, then population health may indeed exacerbate the severity of COVID-19 in LMICs. Understanding the extent to which health conditions endemic to LMICs affect COVID-19 severity is an urgent priority, particularly as policy responses increasingly focus on identifying and isolating high-risk individuals. ${ }^{30}$

Our analysis is also constrained by the limited and changing evidence on risk factors for COVID-19 severity. Based on the availability of existing measures, our model assumed that health condition relative risks are ageinvariant. However, data from New York's epidemiological surveillance system suggest that hypertension and diabetes may contribute more to mortality at younger ages, ${ }^{31}$ which would exacerbate the burden of illness among the young in LMICs. Furthermore, if illness severity and the quality of prior medical management of pre-existing health conditions change mortality risk for the same diagnosis across contexts, applying HRs from England may understate mortality risk in India. Finally, HRs which are not conditioned on infection may reflect infection risk in addition to disease severity risk and thus may not translate directly to the Indian context.

Recognising these limitations, we have posted our analysis on github (see data availability statement), allowing estimates to be calibrated with different risk factors, HRs and data from other countries, as more research on the virus emerges.

\section{Twitter Paul Novosad @paulnovosad}

Contributors All authors had full access to all the data in the study and shared the final responsibility for the decision to submit for publication. All authors saw and approved the final version of the manuscript. The corresponding author attests that all listed authors meet authorship criteria and that no others meeting the criteria have been omitted. All authors had full access to all of the data in the study and take responsibility for the integrity of the data and the accuracy of the data analysis. All authors were equally involved in every part of the study, including conception, analysis and writing. PN, RJ, AC and SA were involved in the paper conception, data analysis, interpretation and writing.

Funding Asher and Novosad received funding from Emergent Ventures, with application number \#466.

Competing interests None declared.

Patient consent for publication Not required.

Ethics approval This study was exempted from human subjects review by the Institutional Review Board at Dartmouth College.

Provenance and peer review Not commissioned; externally peer reviewed.

Supplemental material This content has been supplied by the author(s). It has not been vetted by BMJ Publishing Group Limited (BMJ) and may not have been peer-reviewed. Any opinions or recommendations discussed are solely those of the author(s) and are not endorsed by BMJ. BMJ disclaims all liability and responsibility arising from any reliance placed on the content. Where the content includes any translated material, BMJ does not warrant the accuracy and reliability of the translations (including but not limited to local regulations, clinical guidelines, terminology, drug names and drug dosages), and is not responsible for any error and/or omissions arising from translation and adaptation or otherwise.

Open access This is an open access article distributed in accordance with the Creative Commons Attribution Non Commercial (CC BY-NC 4.0) license, which permits others to distribute, remix, adapt, build upon this work non-commercially, and license their derivative works on different terms, provided the original work is properly cited, appropriate credit is given, any changes made indicated, and the use is non-commercial. See: http://creativecommons.org/licenses/by-nc/4.0/.

\section{ORCID iDs}

Paul Novosad http://orcid.org/0000-0001-8331-6630

Radhika Jain http://orcid.org/0000-0002-4976-2167

Alison Campion http://orcid.org/0000-0001-9820-6450

Sam Asher http://orcid.org/0000-0002-2584-8011 


\section{REFERENCES}

1 World Health Organization. Coronavirus disease (COVID-19) Situation Report - 142, 2020.

2 Onder G, Rezza G, Brusaferro S. Case-Fatality rate and characteristics of patients dying in relation to COVID-19 in Italy. JAMA 2020;323:1775-6.

3 Dowd JB, Andriano L, Brazel DM, et al. Demographic science AIDS in understanding the spread and fatality rates of COVID-19. Proc Natl Acad Sci U S A 2020;117:9696-8.

4 Walker PGT, Whittaker C, Watson OJ, et al. The impact of COVID-19 and strategies for mitigation and suppression in low- and middleincome countries. Science 2020;369:eabc0035.

5 Oliveira MHSde, Wong J, Lippi G, et al. Analysis of clinical and demographic heterogeneity of patients dying from COVID-19 in Brazil versus China and Italy. Braz J Infect Dis 2020;24:273-5.

6 Updates on COVID-19: may 21 2020. Ministry of health and family welfare, government of India, 2020. Available: https://pib.gov.in/ PressReleseDetailm.aspx?PRID=1625744 [Accessed 22 Jun 2020].

7 McCoy $\mathrm{T}$, Traiano $\mathrm{H}$. In the developing world, the coronavirus is killing far more young people, 2020. Available: https://www. washingtonpost.com/world/the_americas/coronavirus-brazil-killingyoung-developing-world/2020/05/22/f76d83e8-99e9-11ea-ad79eef7cd734641_story.html [Accessed 22 Jun 2020].

8 Laxminarayan R, Wahl B, Dudala SR, et al. Epidemiology and transmission dynamics of COVID-19 in two Indian states. Science 2020;370:691-7.

9 Minu P, Ray D, Subramanian S. Decoding India's Low Covid-19 Case Fatality rate. NBER Work Pap, 2020.

10 loannidis JPA, Axfors C, Contopoulos-loannidis DG. PopulationLevel COVID-19 mortality risk for non-elderly individuals overall and for non-elderly individuals without underlying diseases in pandemic epicenters. Environ Res 2020;188:109890.

11 Gilbert M, Pullano G, Pinotti F, et al. Preparedness and vulnerability of African countries against importations of COVID-19: a modelling study. Lancet 2020;395:871-7.

12 Pearson $\mathrm{CAB}$, van Zandvoort $\mathrm{K}$, Jarvis $\mathrm{Cl}$, et al. Modelling projections for COVID19 epidemic in India. LSHTM CMMID COVID-19 Working group, 2020

13 Richardson S, Hirsch JS, Narasimhan M, et al. Presenting characteristics, comorbidities, and outcomes among 5700 patients hospitalized with COVID-19 in the new York City area. JAMA 2020;323:2052-9.

14 Wu Z, McGoogan JM. Characteristics of and Important Lessons From the Coronavirus Disease 2019 (COVID-19) Outbreak in China: Summary of a Report of 72314 Cases From the Chinese Center for Disease Control and Prevention. JAMA 2020;323:1239-42.

15 Zhou F, Yu T, Du R, et al. Clinical course and risk factors for mortality of adult inpatients with COVID-19 in Wuhan, China: a retrospective cohort study. Lancet 2020;395:1054-62.

16 Davies NG, Klepac P, Liu Y, et al. Age-Dependent effects in the transmission and control of COVID-19 epidemics. Nat Med 2020;26:1205-11. doi:10.1038/s41591-020-0962-9

17 van Zandvoort $\mathrm{K}$, Jarvis $\mathrm{Cl}$, Pearson $\mathrm{CAB}$, et al. Response strategies for COVID-19 epidemics in African settings: a mathematica modelling study. BMC Med 2020;18:324. doi:10.1186/s12916-02001789-2

18 Banerjee A, Pasea L, Harris S, et al. Estimating excess 1-year mortality associated with the COVID-19 pandemic according to underlying conditions and age: a population-based cohort study. Lancet 2020;395:1715-25.

19 Cabore JW, Karamagi HC, Kipruto H, et al. The potential effects of widespread community transmission of SARS-CoV-2 infection in the world Health organization African region: a predictive model. BMJ Glob Health 2020;5:e002647.

20 Ghisolfi S, Almås I, Sandefur JC, et al. Predicted COVID-19 fatality rates based on age, sex, comorbidities and health system capacity. BMJ Glob Health 2020;5:e003094.

21 Clark A, Jit M, Warren-Gash C, et al. Global, regional, and national estimates of the population at increased risk of severe COVID-19 due to underlying health conditions in 2020: a modelling study. Lancet Glob Health 2020;8:e1003-17.

22 Williamson EJ, Walker AJ, Bhaskaran K, et al. Factors associated with COVID-19-related death using OpenSAFELY. Nature 2020;584:430-6.

23 Petrilli CM, Jones SA, Yang J, et al. Factors associated with hospital admission and critical illness among 5279 people with coronavirus disease 2019 in New York City: prospective cohort study. BMJ 2020;369:m1966

24 Lifestyles Team, NHS Digital. Health survey for England 2018, 2019. Available: https://digital.nhs.uk/data-and-information/publications/ statistical/health-survey-for-england/2018

25 World Health Organization. World Health organization and international diabetes fund. definition and diagnosis of diabetes mellitus and intermediate hyperglycemia, 2006. https://www.who. int/diabetes/publications/Definition\%20and\%20diagnosis\%20of\% 20diabetes_new.pdf

26 Global Burden of Disease Collaborative Network. Global burden of disease study 2017 (GBD 2017) results. Seattle, United States: Institute for Health Metrics and Evaluation (IHME), 2018. http://ghdx. healthdata.org/gbd-results-tool

27 McLean S, Hoogendoorn M, Hoogenveen RT, et al. Projecting the COPD population and costs in England and Scotland: 2011 to 2030. Sci Rep 2016;6:31893.

28 Leung JM, Sin DD. Smoking, ACE-2 and COVID-19: ongoing controversies. Eur Respir J 2020;56. doi:10.1183/13993003.017592020. [Epub ahead of print: 16 Jul 2020].

29 Cummings MJ, Baldwin MR, Abrams D, et al. Epidemiology, clinical course, and outcomes of critically ill adults with COVID-19 in New York City: a prospective cohort study. medRxiv 2020;395:1763-70. doi:10.1016/S0140-6736(20)31189-2

30 Das J, Sánchez-Páramo C. Smart containment: how low-income countries can tailor their COVID-19 response, 2020. Available: https://blogs.worldbank.org/voices/smart-containment-how-lowincome-countries-can-tailor-their-covid-19-response [Accessed 20 Jun 2020].

31 Covid19 tracker- fatalities: top 10 comorbidities by age group, 2020 . Available: https://covid19tracker.health.ny.gov/views/NYS-COVID19Tracker/NYSDOHCOVID-19Tracker-Fatalities?\%3 